\title{
DIAGNÓSTICO DE LA ACTIVIDAD PRODUCTIVA DEL FRIJOL (Phaseolus vulgaris L.) EN LA REGIÓN BRUNCA DE COSTA RICA: COSECHA 1995-1996/
}

\author{
Juan Carlos Hernández², Rodolfo Araya ${ }^{3}$, Walter González ${ }^{3}$
}

\begin{abstract}
RESUMEN
Diagnóstico de la actividad productiva del frijol (Phaseolus vulgaris L.) en la Región Brunca de Costa Rica: Cosecha 1995-1996. Se seleccionaron nueve localidades caracterizadas por su tradición en la siembra de frijol para efectuar un monitoreo y diagnosticar la situación de esta actividad productiva. Con base en encuestas y visitas a fincas de agricultores se obtuvo que en la mayoría de las localidades predominó el empleo de variedades criollas, de las que se caracterizaron por su precocidad las de mayor uso comercial. Las variedades mejoradas mostraron como desventaja su mayor ciclo vegetativo lo que influyó en mayor deterioro del grano debido a la incidencia de lluvia durante la época de cosecha. La calidad de la semilla así como su disponibilidad fueron los principales problemas, además del inóculo, principalmente de Antracnosis, que estaba presente en la semilla y en la mayoría de estos suelos frijoleros. La Mustia Hilachosa fue el patógeno que más incidió en los campos de los agricultores, seguido por la Mancha Angular y Antracnosis. También las malezas constituyeron otro problema en la región Brunca.
\end{abstract}

\begin{abstract}
Diagnosis of the productive activity of the bean (Phaseolus vulgaris L.) in the Brunca Region from Costa Rica: Harvest time: 1995-1996. Nine localities were selected by their tradition in the bean cultivation in order to carry out a survey and diagnose of the situation of this productive activity. Based on surveys and visits to properties of farmers, it was that in the majority of the localities prevailed the use of Creole varieties. Creole varieties with a major commercial use were important for their precocity. A longer vegetative cycle of the improved varieties was a disadvantage which caused grain deterioration during the rain season. Quality and seed availability were the main problems. Inoculants of Antracnosis was found in the field and in the seeds. Web blight was an important pathogen affecting bean crops followed by leaf spot anthracnose. It was found that weeds were an important problem in the Brunca region.
\end{abstract}

\section{INTRODUCCIÓN}

La práctica del diagnóstico en la agricultura es un instrumento valioso para la asignación de recursos destinados a la investigación. La determinación de los principales problemas, como lo son aquellos factores que causan reducción en la productividad del frijol, es básica para definir estrategias y prioridades. Así, los programas de investigación y acción social pueden orientar sus fortalezas hacia el alcance de soluciones de acuerdo a un plazo de urgencia.

El diagnóstico toma en cuenta, no sólo, aquellos componentes que limitan la productividad, sino también, la producción en general. La condición social de los agricultores y de la mano de obra, la topografía y tipo de suelos, la necesidad de una producción sostenible, el mercadeo, la asistencia técnica y el aspecto financiero son otros factores que llegan a ocupar un lugar muy importante en la definición de un plan de mejoramiento genético.

Debido a la importancia de la disponibilidad de información actualizada sobre la situación agroeconómica de la actividad económica de los productores en las principales Regiones Frijoleras de Costa Rica, se efectuó el presente estudio con el objetivo principal de determinar las principales limitantes agronómicas que se dan en la producción de frijol en la Región Brunca.

1 Inscrito en la Vicerrectoría de Investigación de la Universidad de Costa Rica. 736-91315 y financiado por PROFRIJOL y Ministerio de Agricultura y Ganadería de Costa Rica.

2 Ministerio de Agricultura y Ganadería. Dirección Regional Brunca. Pérez Zeledón, San José, Costa Rica.

3 Estación Experimental Fabio Baudrit Moreno (EEFBM), Universidad de Costa Rica. Apartado Postal 183-4050 Alajuela, Costa Rica. E-mail: pccmca@sol.racsa.co.cr., wgonzale@cariari.ucr.ac.cr, respectivamente. 


\section{MATERIALES Y MÉTODOS}

\section{Periodo y estrategia del estudio}

Durante el periodo 1995-1996, se seleccionaron nueve localidades dentro de la Región Brunca, caracterizadas por su tradición en la siembra de frijol: 1)San Vito de Coto Brus, 2)Buenos Aires, 3)Uvita, 4)Pejibaye, 5)Puerto Jiménez, 6)Potrero Grande, 7)Rivas, 8)Puerto Cortes y 9)Piedras Blancas (Cuadro 1). En cada localidad se seleccionaron una o dos fincas de agricultores, cuya siembra de frijol recibió seguimiento.

\section{Región de estudio}

La Región Brunca de Costa Rica es la segunda en importancia en cuanto a producción se refiere. En el periodo 1990-1991, esta región produjo 9584 t en una área de 26250 ha, lo cual representó un 27,77\% y $37,73 \%$ de la producción y el área a nivel nacional, respectivamente. La mayor parte del área sembrada de esta Región (7000 ha; 26,67\% del área total del país), se encuentra en el Cantón de Pérez Zeledón (MAGPRIAG 1991; Salazar 1996) y predominan los pequenos productores bajo el sistema de siembra en espeque y tapado.

En general, su precipitación promedio anual varía desde 2424 mm en Pejibaye a 3970 mm, en Puerto Jiménez; mientras que la temperatura promedio anual, de $22,2{ }^{\circ} \mathrm{C}$ en Pejibaye, a $27,0{ }^{\circ} \mathrm{C}$ en Corredores y la humedad relativa, de $78,3 \%$ en Puerto Jiménez a $87,7 \%$, en Pejibaye (MAG-PRIAG 1991). Predominan suelos ultisoles e inceptisoles. Los ultisoles son los de más amplia distribución en la región y se caracterizan por ser profundos, de color pardo-rojizo, pesados; bien estructurados, moderadamente permeables y poco fértiles; son de relieve moderadamente ondulados a escarpados. Los inceptisoles, están constituidos por suelos aluviales y coluviales, con drenaje desde bueno hasta pobre. Los suelos de esta región se ubican en las clases VII y VI, son en su mayoría suelos de poca vocación agrícola, que presentan como limitante, principalmente la elevada pendiente. De manera más específica, en el Cuadro 1 se describen los sitios geográficamente y sus características de clima y suelos.

Se efectuó una revisión de literatura, entrevistas con agricultores y técnicos, y también una encuesta utilizando el cuestionario elaborado por el Ing. Abelardo Viana Ruano, Economista del Programa Cooperativo de Frijol para Centroamérica, México y El Caribe (PROFRIJOL). Este cuestionario incluyó la toma de datos sobre: 1)la parcela del agricultor, 2)la semilla empleada, 3)la pendiente del suelo, 4)la densidad y el arreglo espacial de siembra y 5)tres visitas al campo del agricultor (durante la siembra, 10-20 días después de la siembra, 35-40 días después de la siembra y a la madurez fisiológica).

\section{RESULTADOS Y DISCUSIÓN}

\section{Producción y consumo}

En el Cuadro 2 se presentan aspectos sobre la producción y el consumo por localidad en la Región Brunca. Sobresale una mayor área de siembra y producción total en Potrero Grande y San Vito De Jaba y luego, en

Cuadro 1. Descripción geográfica de las áreas bajo estudio en la Región Brunca, 1995-1996.

\begin{tabular}{ll}
\hline Zona & Descripción geográfica \\
\hline Pejibaye & $\begin{array}{l}\text { Se ubica al Noroeste de la Región Brunca, comprende los distritos de Platanares, Pejibaye y parte de los Distri- } \\
\text { tos Daniel Flores Pilas y colinas; temperatura } 25-32{ }^{\circ} \mathrm{C} \text {, precipitación anual } 2000 \mathrm{~mm} \text {; suelos ultisoles, incepti- } \\
\text { soles, textura limosa, arcillo limosa y laminar granulada, pendiente } 5-60 \% .\end{array}$ \\
\hline Buenos Aires & $\begin{array}{l}\text { Zonas de } 100 \text { a } 800 \mathrm{msnm} \text {, suelos rojos, bajo contenido de materia orgánica. Mayoría de pequeños propietarios } \\
\text { y áreas de siembra menores a } 2 \mathrm{ha.} 38 \% \text { del área es reserva indígena ; temperatura } 28-33^{\circ} \mathrm{C} \text {, precipitación } 2500-\end{array}$ \\
& $\begin{array}{l}3000 \mathrm{~mm} \text {, altitud } 100-800 \mathrm{msnm} ; \text { suelos rojos, arcillosos de bajo contenido de materia orgánica y alta concen- } \\
\text { tración de aluminio, pendiente } 45 \% . \text { Potrero-Grande y San Vito de Jaba Comprende desde Paso Real hasta Águi- }\end{array}$ \\
& $\begin{array}{l}\text { la Buena de Coto Brus ; temperatura } 18-30{ }^{\circ} \mathrm{C} \text {, precipitación anual } 2250-3500 \text { mm ; suelos de origen volcánico, } \\
\text { textura arcillosa y arcillo arenosa. La mayoría de los productores son pequeños, la actividad se concentra en si- } \\
\text { tios a una altitud entre los } 183 \text { y } 820 \mathrm{msnm} \text {. En la Zona de Coto Brus, el frijol no es la actividad principal. }\end{array}$ \\
\hline
\end{tabular}

San Isidro La actividad frijolera no es la más importante, existe una gran variabilidad de las condiciones climáticas ya que se extiende desde la zona costera hasta la cordillera de Talamanca ; temperatura $18-30{ }^{\circ} \mathrm{C}$, precipitación anual 2500-3500 mm, altitud 200-1700 msnm ; suelos de gran variabilidad. El acceso a las comunidades es muy difícil por distancias y estado de caminos. vos, de alta variabilidad. Predomina el sistema de siembra tapado, con bajos rendimientos y un bajo nivel técnico. 
Cuadro 2. Información de la producción comercial de frijol, área sembrada, época de siembra y consumo en las localidades de estudio. Región Brunca, Costa Rica. Periodo 1995-1996.

\begin{tabular}{|c|c|c|c|c|c|}
\hline Aspecto & Pejibaye & $\begin{array}{c}\text { Buenos } \\
\text { Aires }\end{array}$ & $\begin{array}{c}\text { Potrero Grande } \\
\text { San Vito de Coto Brus }\end{array}$ & San Isidro & Uvita \\
\hline Área sembrada (ha) & 2000 & 2500 & 3600 & 1600 & 150 \\
\hline Producción total (t) & 1472 & 1380 & 2484 & 874 & 55,2 \\
\hline Producción Promedio (kg/ha) & 736 & 552 & 690 & 546 & 368 \\
\hline Consumo per capita ( $\mathrm{kg} / \mathrm{año})$ & 23 & 8 & - & - & - \\
\hline Extensión de las fincas (ha) & $2-3$ & $2-5$ & 3 & 8 & $7-15$ \\
\hline Período siembra Primera & mayo & abril-mayo & mayo & $2^{\text {a abril-mayo }}$ & -- \\
\hline Período siembra Postrera & oct.-nov. & set.-oct. & set.-dic. & $4^{\text {a }}$ oct.-dic. & $1^{\text {a }}$ oct. \\
\hline
\end{tabular}

Pejibaye y Buenos Aires; San Isidro en menor escala y Uvita en último lugar. No obstante, se da un mayor rendimiento en Pejibaye que superó ligeramente, a Potrero Grande y San Vito de Jaba. El rendimiento de Buenos Aires y San Isidro fue semejante al promedio nacional; mientras que en Uvita se da el rendimiento más bajo, pero se asocia a fincas de mayor tamaño, al igual que en San Isidro. Esto indica que fincas de tamaño inferior a tres hectáreas tuvieron mayor rendimiento.

La localidad que siembra frijol en la primer época de siembra (abril-mayo) es Pejibaye y en pocas areas de Buenos Aires, las demás localidades siembran frijol solo en la segunda época.

\section{Variedades}

En Pejibaye, Buenos Aires y Potrero Grande, predominó el empleo de variedades criollas, Cuadro 3. La principal ventaja de estas variedades es la precocidad, pero como principal desventaja está la susceptibilidad a la Antracnosis. En la localidad de San Isidro predominaron las variedades mejoradas pero con la desventaja de su largo ciclo vegetativo y susceptibilidad a la "humedad" (rápida germinación de los granos en las vainas cuando hay temporal).

En relación con las variedades promisorias (material no liberado oficialmente como mejorado o bajo un esquema de producción de semilla) se mostró el interés en disponer de más semilla de los materiales discutidos a continuación. En Buenos Aires la variedad mejorada Puricise y UCR 55 se señalaron como buenas para baja fertilidad (estos materiales fueron seleccionados por su resistencia a la Antracnosis pero luego se determinó su tolerancia a la baja fertilidad), pero no está disponible la semilla. En la Uvita se destacó otra variedad mejorada, la Chorotega pero no hay disponibilidad de semilla.
Predominaron las variedades criollas, debido principalmente a su ciclo vegetativo precoz. Las variedades mejoradas, aunque con buen potencial de rendimiento, mostraron ciclos vegetativos muy tardíos (hasta 23 días más que la variedad criolla Sacapobres, la más sembrada en la zona) además de arquitectura no adecuada a sus sistemas de producción. Esto evidencia para esta zona que el mejoramiento genético actual no ha considerado estos factores en su esquema de obtención de variedades mejoradas y sólo se ha basado en la obtención de variedades para sistemas tecnificados.

Se confirma el uso principal de variedades criollas, bajo el principal sistema de siembra en esta zona, el espeque (Cuadro 4), debido a que el sistema tapado, por la poca disponibilidad de terrenos apropiados, no es posible efectuarlo sin correr el riesgo de perderlo por incidencia de malezas. La siembra se hace en ladera. La densidad de siembra tuvo un rango de variación de hasta 117 mil semillas/ha. Esta varió según el tipo de variedad criolla que empleen así como la experiencia del productor.

La semilla mejorada procedió principalmente del Consejo Nacional de Producción (CNP). Se denotó que la calidad de la semilla así como su disponibilidad son los principales problemas que los pequeños productores de frijol indicaron. Es de considerar además el inóculo, principalmente de Antracnosis, que está presente en la semilla y en la mayoría de los suelos frijoleros. La solución a este problema se podría enfocar desde el mejoramiento genético de las variedades locales, aprovechando su ciclo vegetativo precoz así como su adaptación edafoclimática, como de la introducción de variedades mejoradas pero seleccionadas para estas condiciones de suelos y manejo agronómico. 
Cuadro 3. Ventajas y desventajas de las variedades de frijol utilizadas y variedades promisorias no utilizadas en la Región Brunca de Costa Rica, 1995-96.

\begin{tabular}{|c|c|c|c|c|c|c|}
\hline \multirow[t]{2}{*}{ ZONA } & \multicolumn{3}{|c|}{ VARIEDADES UTILIZADAS } & \multicolumn{3}{|c|}{ VARIEDADES PROMISORIAS NO UTILIZADAS } \\
\hline & Nombre & Problemas & Ventajas & Nombre & Ventajas & $\begin{array}{l}\text { Razones Para } \\
\text { No Utilizarlas }\end{array}$ \\
\hline Pejibaye & $\begin{array}{l}\text { Sacapobres } \\
\text { Aguacatillo } \\
\text { Brunca } \\
\text { Talamanca }\end{array}$ & $\begin{array}{l}\text { Susceptible } \\
\text { Antracnosis } \\
\text { Susceptible a } \\
\text { Mustia Hilachosa } \\
\text { Mustia Hilachosa } \\
\text { Mustia Lorito verde }\end{array}$ & $\begin{array}{l}\text { Ciclo corto, alto } \\
\text { rendimiento } \\
\text { Ciclo corto, alto } \\
\text { rendimiento } \\
\text { Alto rendimiento } \\
\text { Alto rendimiento }\end{array}$ & $\begin{array}{l}\text { RAB } 572 \\
\text { Puricise }\end{array}$ & $\begin{array}{l}\text { Buena apariencia Alto } \\
\text { rendimiento } \\
\text { Tolerante al bajo } \\
\text { fósforo } \\
\text { Resistente Chasparria }\end{array}$ & No está liberado \\
\hline Buenos Aires & $\begin{array}{l}\text { Sacapobres } \\
\text { Chimbolo negro } \\
\text { Chimbolo rojo } \\
\text { Kiubra } \\
\text { Talamanca } \\
\text { Brunca }\end{array}$ & $\begin{array}{l}\text { Susceptible a } \\
\text { Antracnosis }\end{array}$ & $\begin{array}{l}\text { Precoz, resistente a } \\
\text { Chasparria } \\
\text { Alto rendimiento } \\
\text { Alto rendimiento } \\
\text { Resistente, buen } \\
\text { aspecto } \\
\text { Alto rendimiento } \\
\text { Alto rendimiento }\end{array}$ & $\begin{array}{l}\text { Puricise } \\
\text { Chirripó Rojo }\end{array}$ & $\begin{array}{l}\text { Tolerancia, } \\
\text { bajo fósforo } \\
\text { Resistente Mosaico } \\
\text { Dorado }\end{array}$ & $\begin{array}{l}\text { No está liberado } \\
\text { No está probado } \\
\text { en la zona. }\end{array}$ \\
\hline $\begin{array}{l}\text { Potrero Grande } \\
\text { y San Vito }\end{array}$ & $\begin{array}{l}\text { Chimbolo } \\
\text { Vaina blanca } \\
\text { Sacapobres. }\end{array}$ & $\begin{array}{l}\text { Bajo rendimiento } \\
\text { enfermedades } \\
\text { Susceptible Mustia y } \\
\text { Antractosis } \\
\text { Susceptible a } \\
\text { Antracnosis y } \\
\text { Mustia }\end{array}$ & $\begin{array}{l}\text { No se indicaron } \\
\text { crecimiento }\end{array}$ & No se conocen & & \\
\hline Isidro & $\begin{array}{l}\text { Brunca } \\
\text { Huetar } \\
\text { Chorotega }\end{array}$ & $\begin{array}{l}\text { Hábito crecimiento } \\
\text { Sucept. a humedad } \\
\text { Baja productividad }\end{array}$ & $\begin{array}{l}\text { Alta productividad } \\
\text { Hábito crecimiento } \\
\text { Alta productividad }\end{array}$ & No se conocen & & \\
\hline & Negro Huasteco & Adaptación & Resiste humedades & & & \\
\hline & Locales & $\begin{array}{l}\text { Heterogeneidad de } \\
\text { las variedades }\end{array}$ & $\begin{array}{l}\text { Adaptación a las } \\
\text { zonas }\end{array}$ & & & \\
\hline Uvita & Criollos & Ataque plagas & $\begin{array}{l}\text { Bajo costo de } \\
\text { producción }\end{array}$ & Chorotega & Alta producción & $\begin{array}{l}\text { Alto costo de } \\
\text { semilla }\end{array}$ \\
\hline
\end{tabular}

\section{Manejo agronómico del frijol}

En todas las localidades estudiadas, con excepción de Uvita, se dieron dos periodos de siembra denominados: primera siembra y postrera. Los meses en que se dan estos periodos se presentan en el Cuadro 2.

Por lo general, el terreno en que se siembra el maíz en la primera siembra es utilizado para el cultivo del frijol, lo que no ocurre en Pejibaye (Costa Rica, 1991'a). De esta forma, la preparación se hace con base en el desarrollo de las malezas existentes: si hay malezas muy desarrolladas efectúan una chapea previa y después hacen una aplicación de herbicida quemantes (Paraquat); si la maleza existente es reducida, sólo aplican el herbicida quemante.
En Pejibaye, la época de siembra del frijol fue abril, entre la tercera y cuarta semana, y en mayo, entre la primera y segunda semana. La siembra de maíz se ejecutó en el mes de setiembre (segunda quincena), con énfasis a finales del mes. La "tapa" se efectuó a finales del mes de setiembre lo que coincidió con otros autores (Costa Rica 1991a). El "frijol tapado" se lleva a cabo mediante el sistema tradicional (Monge et al; 1987). Para el sistema frijol sembrado, la preparación de terreno se realizó de dos formas: 1)una chapea manual a "cuchillo" aproximadamente un mes antes de la siembra, posteriormente, ocho días antes de la siembra, ponen fuego en la maleza cortada; 2)chapea manual un mes antes de la siembra y la aplicación de un herbicida quemante a base de Paraquat, cuando las plantas cortadas retoñen (unos pocos agricultores utilizan el glifosato). Para la siembra del frijol esperan que se de la germinación de malezas y hacen una aplicación de herbicida quemante (Paraquat). 
Cuadro 4. Calidad de la semilla, tipo de preparación del terreno y su pendiente en finca de los agricultores, en la Región Brunca de Costa Rica, 1995-1996.

\begin{tabular}{|c|c|c|c|c|c|c|}
\hline Finca & Variedad & $\begin{array}{c}\text { Germinación } \\
\%\end{array}$ & $\begin{array}{c}\text { \# Semillas/ } \\
\text { ha }\end{array}$ & Sistema & $\begin{array}{c}\text { Preparación } \\
\text { terreno }\end{array}$ & $\begin{array}{l}\text { Pendiente } \\
\text { terreno \% }\end{array}$ \\
\hline 1 & Mexicano rojo & 85 & 225806 & Espeque & Chapea glifosato. Paraquat & 25 \\
\hline 2 & Mexicano vaina blanca (Negro) & 87 & 177055 & Espeque & Chapea y quema Paraquat & 35 \\
\hline 3 & Chimbolo Rojo & 84 & 238000 & Espeque & Chapea y quema Paraquat & 40 \\
\hline 4 & Talamanca & 90 & 165000 & Espeque & Chapea y Paraquat & 30 \\
\hline 5 & Talamanca & 78 & 173657 & Espeque & Chapea y Paraquat & 42 \\
\hline 6 & Brunca & 80 & 147477 & Espeque & Chapea y Paraquat & 35 \\
\hline 7 & México 80-RAB 572-BAT 76 & 97 & 266664 & Espeque & Asocio con café & 20 \\
\hline 8 & Frijol Negro & 92 & 171992 & Espeque & Chapea y Paraquat & 50 \\
\hline 90 & Talamanca & 90 & 222222 & Tapado & -- & 30 \\
\hline
\end{tabular}

Las distancias de siembra utilizadas en frijol son muy variables. Entre sitios de siembra (siembra a espeque) varió de 30 a $60 \mathrm{~cm}$ e igualmente, las distancias entre surcos de 30 y $60 \mathrm{~cm}$ y tres semillas por sitio de siembra. Estas distancias generan una población entre 166 mil y 200 mil plantas por hectárea acorde con lo afirmado por varios autores (Días et al; 1990; Morales y Hernández, 1991). Los agricultores siembran todos los años en el mismo terreno. La fertilización predominante para frijol en esta zona, se basó en la aplicación de la fórmula comercial 10-30-10 o 12-24-12, durante dos épocas: uno que va desde la siembra hasta los 10 días después y la otra, entre 15 y 20 días después de la siembra. La dosis de aplicación, varió entre 50 y $150 \mathrm{~kg} / \mathrm{ha}$.

En esta zona, los agricultores tienen muy poca posibilidad de rotar los terrenos. No es factible la producción de maíz, con los actuales genotipos, sin la aplicación de fertilizantes. Al maíz se le fertiliza con la fórmula comercial 10-30-10 o 12-24-12, aplicada a los entre los 8 y 10 días después de la siembra. La segunda fertilización es exclusivamente, a base de nitrógeno (Nutrán) entre los 3040 días después de la siembra. La cantidad de fertilizante de la fórmula comercial 10-3010 varía entre 75 y $200 \mathrm{~kg} / \mathrm{ha}$. La dosis de NUTRAN variaron entre 60 y $200 \mathrm{~kg} / \mathrm{ha}$, lo que concuerda con lo obtenido por González y Hernández (1991).

\section{Manejo de malezas}

La descripción de las malezas según la pendiente del suelo donde se efectuó el monitoreo, se da en el Cuadro 5. El manejo de suelo desnudo, debido al empleo del sistema espeque, favoreció una mayor incidencia de malezas. Se está implementando el manejo de mínima labranza, sin quema de los residuos del cultivo anterior, pero se requiere además, la capacitación en el manejo efectivo de las malezas con herbicidas, debido a que con el empleo de cobertura no sería suficiente al inicio para un control económico. Sobre el uso de herbicidas, se evidenció que aunque tienen herbicidas específicos para el control de Mozotillo y Chiquizacillo, son de alto costo y se desconoce su empleo oportuno y efectivo.

\section{Patógenos}

Los patógenos más comunes en todas las localidades fueron la mustia Hilachosa, la Antracnosis y la Mancha Angular (Cuadro 6). Para el combate estos patógenos la mejor solución esta en la tolerancia o resistencia genética, combinada con una alta variabilidad genética de variedades comerciales (es común en estas zonas la alta variabilidad genética empleada en sus variedades criollas y la variabilidad intrínseca de cada material criollo debido a que son multilíneas) pero adolecen de grados de resistencias apropiados para uso comercial. Esto implicaría además el cambio de material en ciclos de al menos cinco años, lo que requiere del apoyo de un programa de mejoramiento genético.

Entre las plagas más comunes esta la babosa y las diabróticas. Para las babosas hay combate efectivo con cebos pero las diabróticas, son una plaga del maíz y transmiten el virus del monteado clorótico del Caupi, que produce el "amachado" al frijol. Esto requiere de un plan de manejo regional.

\section{Asistencia técnica}

Entre las principales limitaciones para efectuar la asistencia técnica, estuvo la falta de equipo audiovisual e impreso, falta de vehículo apropiado o ausente para traslado a las fincas. En la metodología se evidencia el trabajo individual con los agricultores, lo cual afecta la difusión de la información actualizada sobre manejo del cultivo y encarece la extensión agrícola (Cuadro 7), lo que evidencia la necesidad de trabajar con grupos organizados de pequeños productores. 
Cuadro 5. Descripción de las malezas asociadas a los suelos en la Región Brunca de Costa Rica, 1995-1996.

\begin{tabular}{|c|c|c|c|c|}
\hline \multirow[t]{2}{*}{ Zona } & \multicolumn{2}{|c|}{ Malezas } & \multicolumn{2}{|c|}{ Suelos } \\
\hline & Frecuentes & Manejo & Frecuentes & Manejo \\
\hline Pejibaye & $\begin{array}{l}\text { Mozotillo } \\
\text { Chiquizacillo (Borreria sp) } \\
\text { Zacate cholo (Rottboellia } \\
\text { conchinchinensi quebrados } \\
\text { Acidez, Baja fertilidad } \\
\text { Inadecuada muertas Obras) } \\
\text { Hierba de sapo }\end{array}$ & $\begin{array}{l}\text { Uso de herbicidas y } \\
\text { coberturas muertas }\end{array}$ & $\begin{array}{l}\text { Muy quebrados } \\
\text { Acidez } \\
\text { Baja fertilidad } \\
\text { Inadecuada textura }\end{array}$ & $\begin{array}{l}\text { Coberturas muertas } \\
\text { Obras físicas, Suelo contorno }\end{array}$ \\
\hline Buenos Aires & $\begin{array}{l}\text { Zacate cholo (Rottboellia } \\
\text { conchinchinensis) } \\
\text { Moriseco (Bidens pilosa) } \\
\text { Escobilla (Sida } \text { sp.) } \\
\text { Platanilla (Heliconia } \text { sp.) } \\
\text { Helecho (Pteridium aquilinu) }\end{array}$ & Paraquat; chapea. & $\begin{array}{l}\text { Baja fertilidad } \\
\text { Alta concentración Fe y Al } \\
\text { Erosión }\end{array}$ & $\begin{array}{l}\text { Aplicación de fertilizantes } \\
\text { Barbecho } \\
\text { Conservación Suelos, } \\
\text { Barbecho cero labranza. }\end{array}$ \\
\hline $\begin{array}{l}\text { Potrero Grande } \\
\text { y San Vito }\end{array}$ & & $\begin{array}{l}\text { No se controla en su } \\
\text { mayoría las malezas. }\end{array}$ & $\begin{array}{l}\text { Topografía (erosión) } \\
\text { Alta fijación de fósforo }\end{array}$ & $\begin{array}{l}\text { Conservación de Suelos } \\
\text { Análisis químico. }\end{array}$ \\
\hline San Isidro & $\begin{array}{l}\text { Zacate peludo (Paspalun } \\
\text { paniculatum) } \\
\text { Muriseco (Bidens pilosa) } \\
\text { Talqueza } \\
\text { Coyolillo (Cyperus sp.) } \\
\text { Bledo (Amaranthus sp.) }\end{array}$ & $\begin{array}{l}\text { Control con herbicidas } \\
\text { y manual }\end{array}$ & $\begin{array}{l}\text { Bajo Ph, Erosión } \\
\text { Limitaciones } \\
\text { de drenaje } \\
\text { Alto porcentaje de } \\
\text { pendientes. }\end{array}$ & $\begin{array}{l}\text { Uso material orgánico } \\
\text { (gallinaza) } \\
\text { Desagües } \\
\text { Siembra contorno, } \\
\text { labranza mínima, tapado }\end{array}$ \\
\hline Uvita & $\begin{array}{l}\text { Zacate cholo (Rottboellia } \\
\text { conchinchinensis) } \\
\text { Churriestate (Ipomoea } \mathrm{sp} . \text { ) }\end{array}$ & $\begin{array}{l}\text { Herbicida (Fusilade) } \\
\text { No hay control, }\end{array}$ & $\begin{array}{l}\text { Suelos erosionados. } \\
\text { No usa fertilizante }\end{array}$ & $\begin{array}{l}\text { Capacitación en Conservación } \\
\text { de Suelos } \\
\text { Parcela demostrativa con } \\
\text { uso del paquete tecnológico. }\end{array}$ \\
\hline
\end{tabular}

Cuadro 6. Enfermedades y plagas más comunes y su frecuencia y manejo en la Región Brunca de Costa Rica, 1995-1996.

\begin{tabular}{|c|c|c|c|c|}
\hline \multirow[t]{2}{*}{ Zona } & \multicolumn{2}{|c|}{ Enfermedades } & \multicolumn{2}{|c|}{ Plagas } \\
\hline & Frecuentes & Manejo & Frecuentes & Manejo \\
\hline Pejibaye & $\begin{array}{l}\text { Mustia hilachosa } \\
\text { Antracnosis } \\
\text { Virosis }\end{array}$ & $\begin{array}{l}\text { Coberturas muertas y fungicidas } \\
\text { Semilla sana y fungicidas } \\
\text { Control de vectores }\end{array}$ & $\begin{array}{l}\text { Lorito Verde } \\
\text { Babosas, Mosca blanca } \\
\text { Joboto, Gorgojo, Diabroticas }\end{array}$ & $\begin{array}{l}\text { Químico } \\
\text { Cebos } \\
\text { Químico }\end{array}$ \\
\hline Buenos Aires & $\begin{array}{l}\text { Mustia hilachosa } \\
\text { Antracnosis } \\
\text { Mancha angular }\end{array}$ & Aplicación fungicidas & $\begin{array}{l}\text { Vaquita (diabroticas) } \\
\text { Lorito verte } \\
\text { Jobotos, Babosas }\end{array}$ & $\begin{array}{l}\text { Insecticidas } \\
\text { Insecticidas } \\
\text { Caracolicida cebos }\end{array}$ \\
\hline $\begin{array}{l}\text { Potrero Grande } \\
\text { y San Vito }\end{array}$ & $\begin{array}{l}\text { Mustia hilachosa } \\
\text { Antracnosis }\end{array}$ & Ninguna & $\begin{array}{l}\text { Lorito verde } \\
\text { Joboto } \\
\text { Babosa }\end{array}$ & $\begin{array}{l}\text { Insecticidas follaje } \\
\text { Insecticida al suelo } \\
\text { Caracolicida } \\
\text { (Metaldehido }\end{array}$ \\
\hline San Isidro & $\begin{array}{l}\text { Mustia hilachosa } \\
\text { Antracnosis }\end{array}$ & $\begin{array}{l}\text { Fungicidas (Dithane, Benlate, } \\
\text { Brestan } \\
\text { Fungicidas (Dithane, Benlate, } \\
\text { Brestan) }\end{array}$ & $\begin{array}{l}\text { Diabroticas (diabroticas) } \\
\text { Grillos } \\
\text { Pájaros }\end{array}$ & $\begin{array}{l}\text { Caracolicidas } \\
\text { Insecticida (Tamarón, } \\
\text { Lannat }\end{array}$ \\
\hline Uvita & $\begin{array}{l}\text { Mustia hilachosa } \\
\text { Antracnosis }\end{array}$ & $\begin{array}{l}\text { No } \\
\text { No }\end{array}$ & $\begin{array}{l}\text { Babosas } \\
\text { Diabroticas (diabroticas) } \\
\text { Pajuilas (aves) }\end{array}$ & $\begin{array}{l}\text { Cebos } \\
\text { No } \\
\text { No }\end{array}$ \\
\hline
\end{tabular}


Cuadro 7. Asistencia técnica en frijol: métodos y limitaciones encontrados en la Región Brunca de Costa Rica, 1995-1996.

\begin{tabular}{|c|c|c|c|c|}
\hline Zona & Como se realiza asesoría & Limitaciones & Quienes planifican & Seguimiento \\
\hline Pejibaye & $\begin{array}{l}\text {-Visitas a finca (individual y } \\
\text { grupal) } \\
\text {-Giras } \\
\text {-Demostraciones en fincas } \\
\text {-Charlas } \\
\text {-Materiales: pizarra (acrílica, } \\
\text { corriente), rotafolios, equipo } \\
\text { audiovisual, boletines }\end{array}$ & $\begin{array}{l}\text { Falta de tiempo: en época de } \\
\text { cosecha se dificulta por mucho } \\
\text { trabajo del productor. } \\
\text { Transporte } \\
\text { Materiales: Equipo audiovisual, } \\
\text { boletines }\end{array}$ & $\begin{array}{l}\text { Con los productores y con } \\
\text { el ERIERegional Trans- } \\
\text { porte técnicos } \\
\text { Materiales actualizado } \\
\text { Atraso Izan comercializ. } \\
\text { A (equipo regional de } \\
\text { investigación y extensión } \\
\text { agrícola). }\end{array}$ & $\begin{array}{l}\text { Visitas a fincas y } \\
\text { conversaciones con los } \\
\text { productores para corroborar } \\
\text { el seguimiento a las } \\
\text { instrucciones }\end{array}$ \\
\hline Buenos Aires & $\begin{array}{l}\text {-Visitas a finca } \\
\text {-Parcelas demostrativas } \\
\text { Cuando se inicia la atención se } \\
\text { realizan demostraciones de } \\
\text { método grupal. }\end{array}$ & $\begin{array}{l}\text { Tiempo: Censo } \\
\text { Agropecuario Regional } \\
\text { Transporte: sólo un vehículo } \\
\text { para seis funcionarios } \\
\text { Capacitación: falta } \\
\text { preparación de los técnicos } \\
\text { Materiales: No hay material } \\
\text { didáctico, no hay material } \\
\text { actualizado } \\
\text { Atraso pago viáticos. }\end{array}$ & $\begin{array}{l}\text { Los encargados de los } \\
\text { programas de granos } \\
\text { básicos }\end{array}$ & \\
\hline $\begin{array}{l}\text { Potrero } \\
\text { Grande y } \\
\text { San Vito }\end{array}$ & $\begin{array}{l}\text {-Actividades grupales } \\
\text { (demostraciones charlas, giras, } \\
\text { días de campo) } \\
\text {-Distribución boletines, y hojas } \\
\text { divulgativas }\end{array}$ & $\begin{array}{l}\text {-Hay mucha área que cubrir y } \\
\text { poco personal, poco interés del } \\
\text { agricultor debido a las } \\
\text { expectativas de comercialización } \\
\text { No se cuenta con material } \\
\text { actualizado. }\end{array}$ & $\begin{array}{l}\text {-Con los jefes inmediatos } \\
\text { y el encargado de granos } \\
\text { básicos de la región }\end{array}$ & $\begin{array}{l}\text {-Por medio de fichas } \\
\text { técnicas en productores de } \\
\text { seguimiento dinámico. }\end{array}$ \\
\hline San Isidro & $\begin{array}{l}\text { No se da asesoría en el campo, } \\
\text { la mayoría utiliza el sistema de } \\
\text { frijol tapado }\end{array}$ & $\begin{array}{l}\text {-Faltan zonas por atender debido } \\
\text { al sistema de atención por } \\
\text { CAB'S. }\end{array}$ & N. D. & No se hace seguimiento \\
\hline Uvita & $\begin{array}{l}\text { Realiza fundamentalmente en la } \\
\text { capacitación grupal, mediante } \\
\text { charlas, también con visita } \\
\text { individual }\end{array}$ & $\begin{array}{l}\text { Transporte: no se cuenta con } \\
\text { vehículos para llegar a los } \\
\text { productores. } \\
\text { No hay participación de los } \\
\text { investigadores hacia las zonas } \\
\text { involucradas. } \\
\text { Productor no dispuesto al cambio. } \\
\text { No hay insumos para charlas y } \\
\text { demostraciones grupales. }\end{array}$ & Equipo de la agencia & $\begin{array}{l}\text { Mediante visitas a las } \\
\text { plantaciones. } \\
\text {-Con entrevistas al } \\
\text { productor en la oficina }\end{array}$ \\
\hline
\end{tabular}

\section{Aspectos socioeconómicos}

De acuerdo con los resultados obtenidos para la región de estudio (Cuadro 8), en este acápite la actividad del frijol se mostró variada en cuanto a sus objetivos; no obstante continúa teniendo el carácter de subsistencia, marginal y. en transición (del alimento para autoconsumo hacia la mercancía). Se presenta aún como una unidad familiar, que coloca su seguridad en la tierra y no en el dinero, pero con cambios que buscan la comercialización debido a la asociación de cultivos.

El frijol como cultivo se manifiesta como una solución a la nutrición, especialmente para pequeños productores de escasos recursos, baja escolaridad, viviendo en sitios marginales de difícil acceso, en las zonas rurales; pero como una actividad comercial que tiende a ser competente; que se logra colocar en el mercado y satisface diferentes sector de las necesidades de la sociedad.

La experiencia de los productores de cultivar frijol varió de 12 a 30 años, la que se consideró amplia y tendiente a ser mayor que 17 años. El principal uso que se le da al grano es para la venta. El 56\% de los productores involucrados en el estudio vendieron del 80 al $96 \%$ de su producción; un $33 \%$ de ellos vendieron del 40 al $60 \%$ y el resto tendieron al autoconsumo. Pero además se dejan grano para emplearlo como semilla, lo que influye en la gran contaminación del grano con patógenos como antracnosis, mancha angular y mustia hilachosa, y favorece, aún más, la incidencia de estos patógenos en el cultivo. Del total de la producción, el agricultor destina de un $3,6 \%$ a un $10 \%$ a semilla. 
Cuadro 8. Condiciones socioeconómicas, poscosecha y de comercialización del frijol (Phaseolus vulgaris L.) en la Región Brunca de Costa Rica, 1995-1996.

\begin{tabular}{lll}
\hline Zona & \multicolumn{1}{c}{$\begin{array}{c}\text { Información } \\
\text { Socioeconómicos }\end{array}$} & \multicolumn{1}{c}{ Poscosecha y comercialización } \\
\hline Pejibaye & $\begin{array}{l}\text { Productores de bajos y escasos recursos económicos, } \\
\text { los propietarios siembran 2 ha a, otros alquilan o } \\
\text { cultivan con porcentajes sobre cosecha. }\end{array}$ & $\begin{array}{l}\text { Se recolecta en bultos y se vende casi inmedia- } \\
\text { tamente, el 90\% es comercializado por el interme- } \\
\text { diario,el restante 10\% mediante de las asociaciones } \\
\text { de pro-ductores. }\end{array}$ \\
\hline Buenos Aires & $\begin{array}{l}\text { Familias de cinco hijos promedio, escolaridad } \\
\text { media, ingresos menores a 13000 colones por mes, } \\
\text { en su mayoría dependen de la agricultura }\end{array}$ & $\begin{array}{l}\text { Los agricultores generalmente llenan sus } \\
\text { necesidades de autoconsumo y semilla, } \\
\text { comercializando el sobrante con intermediarios } \\
\text { locales, a precios muy bajos. }\end{array}$ \\
\hline $\begin{array}{l}\text { 13\% de componente indígena en su población } \\
\text { Votrero Grande de acceso en muy mal estado. }\end{array}$ & $\begin{array}{l}\text { Comunidades marginales en su mayoría poco } \\
\text { acceso al médico, algunos emigran a zonas } \\
\text { cafetaleras por temporadas }\end{array}$ & $\begin{array}{l}\text { Comercialización en manos de los intermediarios } \\
\text { y a bajos precios. }\end{array}$ \\
\hline San Isidro & $\begin{array}{l}\text { En la mayoría de las comunidades, el café,caña, } \\
\text { guanábana, mora y hortalizas, la actividad del } \\
\text { frijol es complementaria y no orientada hacia el } \\
\text { autoconsumo. }\end{array}$ & $\begin{array}{l}\text { Malas condiciones de caminos y condiciones } \\
\text { climáticas severas en época de cosechas, bajos } \\
\text { precios. }\end{array}$ \\
\hline Uvita & $\begin{array}{l}\text { Zonas catalogadas como de alta pobreza por sus } \\
\text { bajos ingresos y bajo nivel de escolaridad. }\end{array}$ & $\begin{array}{l}\text { El CNP*/ no ha estado comprando las cosechas } \\
\text { por lo que las pérdidas pos cosecha son grandes. }\end{array}$ \\
\hline
\end{tabular}

*/ Consejo Nacional de Producción

\section{Identificación de problemas}

Problemas agronómicos informados:

Los principales problemas informados por diversos autores en distintas localidades de la región se pueden citan a continuación:

Pejibaye: Chasparria o Mustia Hilachosa, Babosa, Malezas y Jobotos.

Potrero Grande: Mustia Hilachosa, Babosa, Vaquitas y luego Mala Adaptación de Cultivares, Pájaros y Hormigas.

Changuena: Babosas, Chasparria, Mala Adaptación de Cultivares y en segundo orden las Vaquitas, la Maleza "Lechilla", el Zacate "Cholo", los Cortadores y el Chapulín.

Puerto Jiménez: Mustia Hilachosa, Babosas, Hongos de la Raíz, Vaquitas y luego el problema de mala adaptación de cultivares, daño de ratas, exceso de humedad a la cosecha, ataque de hormigas y Jobotos.

Corredores: Se subdivide en dos subzonas : una Pavones que es donde se siembra frijol y la parte baja Laurel donde se hace muy poco. Los problemas en orden de importancia fueron: Mustia Hilachosa, Babosas, Vaquitas, y "Amachamiento".
Problemas agronómicos observados en el campo:

Los principales problemas detectados en el campo se presentan en el Cuadro 9 y se enfatizan los siguientes: 1)Chasparria: causada por el hongo Thanatephorus cucumeris, 2) La Babosa, 3)Diabrotica y 4)Pájaros: las aves arrancan las plántulas para alimentarse del grano; entre ellas se informa de principalmente el zanate. 5)Malezas, debido a un control tardío, motivado por falta de tiempo para realizar las chapeas y el alto costo de los herbicidas, 6)Cortadores y Ratas que se alimentan de la semilla y roe el tallo que causa el volcamiento de la planta, 7)Joboto, 8)Vaneo y Amachamiento: Vainas vanas de pocos granos o con granos muy pequeños. 9)Chapulín y Langosta: el daño es producido principalmente al nivel de plántula, ya que se alimenta de las hojas recién formadas o del tallo. Existen diversos tratamientos agroquímicos para el combate de estas enfermedades: el Mancozeb y el Benomil son los más recomendados (Costa Rica 1991b).

\section{Priorización de problemas:}

La mustia hilachosa es el patógeno que afecta más los campos de los agricultores, seguido por la mancha angular y antracnosis. Las malezas son otro problema de importancia en esta región. 
Cuadro 9. Principales problemas encontrados en las fincas de los productores de frijol (\% de incidencia en el campo) en la Región Brunca de Costa Rica, 1995-96.

\begin{tabular}{ccccccc}
\hline Finca & Mustia & BCMV & Mancha angular & Babosas & Antracnosis & Malezas \\
\hline 1 & 25 & 46 & - & - & - & 30 \\
2 & 20 & 24 & - & - & 10 & 33 \\
3 & 25 & 20 & 14 & - & 8 & 25 \\
4 & 15 & - & 15 & - & - & - \\
5 & 10 & - & 40 & - & 9 & 12 \\
6 & 25 & - & - & - & 11 & 30 \\
7 & 18 & - & - & - & 10 & - \\
8 & 12 & - & 20 & 25 & 22 & - \\
9 & 18 & - & & & & \\
\hline
\end{tabular}

Estos problemas indican la necesidad de un manejo integrado (combate físico químico y varietal en el caso de la mustia hilachosa y la antracnosis) implica la necesidad de rotación con maíz, la incorporacion de residuos vegetales para mejorar la materia organica y ademas la disponibilidad de semilla de alta calidad. Los programas de producción de semilla artesanal han favorecido el manejo mas técnico de los campos de producción de semilla pero como la principal fuente de semilla son las variedades criollas, resulta difícil obtener una semilla sana bajo condiciones favorables al patógeno y de alta presión de inóculo. Esto sugiere la necesidad de producción de semilla básica, bajo condiciones de riego o en áreas diferentes a la Región Brunca en cuanto a incidencia de patógenos e inóculo.

\section{AGRADECIMIENTOS}

Se agradece la participación de los siguientes funcionarios de extensión agrícola, en la activa toma de datos y en la interpretación de la información brindada por los agricultores con base en la encuesta.

\begin{tabular}{ll}
\hline \multicolumn{1}{c}{ Localidad } & Funcionario \\
\hline Puerto Grande & Mario Montero \\
& William Pizarro \\
\hline Buenos Aires & Cecilio Rivera, \\
& Jeiner Carmona, \\
& Gustavo Mosqueira, \\
& Santana Jiménez \\
\hline San Vita de Coto Brus & Nils Hidalgo, \\
& Iván Quesada, \\
\hline San Isidro & Félix Alvarado \\
\hline Ciudad Cortés & Alvaro Vela \\
\hline Uvita & Miguel Acosta \\
\hline Pejibaye & Wilfrido Vargas, \\
& Róger Campos \\
& Eduardo Elizondo \\
& Miguel Chinchilla \\
\hline Puerto Jiménez & Miguel Villarreal \\
\hline Rivas & Alfredo Esquivel \\
& Efrén Sequeira \\
\hline
\end{tabular}

\section{LITERATURA CITADA}

BARRANTES, et al; 1986. Aplicación de la metodología de investigación en fincas: El caso de Guagaral, Región Brunca, Costa Rica, 1985-1986 Ministerio de Agricultura y Ganadería, Dirección Regional Pacífico Sur.

COSTA RICA, 1990. Recomendaciones técnicas del cultivo del frijol. San José, Costa Rica. Consejo Nacional de Producción, Departamento Agrotécnico. 27p.

COSTA RICA, 1991a. Diagnóstico Tecnológico para la Región Brunca de Costa Rica Ministerio de Agricultura y Ganadería, Dirección Regional Pacífico Sur, Programa de estudios agro socioeconómicos San Isidro de El General, Costa Rica.

1991b. Aspectos técnicos sobre cuarenta y cinco cultivos agrícolas de Costa Rica Ministerio de Agricultura y Ganadería,Subdirección de Investigaciones Agrícolas. 560 p.

DÍAZ, C., et al; INCLUIR TODOS LOS AUTORES 1990 Sondeo área de estudio: Boruca, Buenos Aires Curso Regional Interfaces de Investigación en Finca CIMMYT-CIAT, San Isidro de El General, Costa Rica. $30 \mathrm{p}$.

GONZÁLEZ, J. ; HERNÁNDEZ J.C. 1991 Resultados del diagnóstico abreviado en frijol y maíz realizado en el distrito de Potrero Grande, Buenos Aires-Costa Rica.

HERNÁNDEZ, 1991. Labranza mínima: una buena alternativa para proteger los suelos Dirección Regional Pacífico Sur, Ministerio de Agricultura y Ganadería Boletín divulgativo (Sin publicar)

Ministerio de Agricultura y Ganadería-PRIAG (Programa regional de reforzamiento a la investigación agronómica sobre los granos básicos en centroamérica convenio CORECA-CEE/IICA). 1988. Diagnóstico tecnológico para la Región Brunca de Costa Rica. Sub-proyecto IFE-36. Dirección Regional Pacífico Sur (DR-PS), Programa de Estudios Agro-socioeconómicos (PAREASE), ALA 88/23. 
Ministerio de Agricultura y Ganadería-PRIAG (Programa regional de reforzamiento a la investigación agronómica sobre los granos básicos en centroamérica convenio CORECA-CEE/IICA). 1991a. Diagnóstico tecnológico para la Región Brunca de Costa Rica. Sub-proyecto IFE-36. Dirección Regional Pacífico Sur (DR-PS), Programa de Estudios Agro-socioeconómicos (PAREASE), ALA 88/23.

Ministerio de Agricultura y Ganadería-PRIAG (Programa regional de reforzamiento a la investigación agronómica sobre los granos básicos en centroamérica convenio CORECA-CEE/IICA).1991b. Diagnóstico agronómico de los principales sistema de producción de los granos básicos en la región de Potrero Grande, Puerto Jiménez y La Cuesta. San José Costa Rica .
MONGE, J.M.; ARAYA, R.; GONZÁLEZ, W. 1987. Evaluación del frijol (Phaseolus vulgaris L.) bajo el sistema "tapado" en San José, Costa Rica. Boletín técnico, Estación Experimental Fabio Baudrit M. 20 (3): 1-11.

MORALES, Á.; HERNÁNDEZ, J.C.. 1991. Resultados del diagnóstico abreviado en frijol y maíz, realizado en el distrito de Puerto Jiménez, Golfito - Costa Rica.

SALAZAR J. 1996. Situación actual y prespectivas de la producción de frijol en Costa Rica. San José, Costa Rica, Consejo Nacional de Producción. 11 p. 